\title{
PENERAPAN LATIHAN WILLIAM FLEXION DENGAN MC. KENZIE TERHADAP PENURUNAN NYERI PINGGANG BAWAH NON SPESIFIK DI RUMAH SAKIT UMUM LABUANG BAJI MAKASSAR
}

\section{APPLICATION OF WILLIAM FLEXION EXERCISES WITH MC. KENZIE TO REDUCTION OF LOWER BACK PAIN NON SPECIFIC IN THE GENERAL HOSPITAL IN LABUANG BAJI MAKASSAR}

\author{
Kasrina Karim 1 , Suharto², Darwis Durahim³ \\ Jurusan Fisioterapi Poltekkes Makassar
}

\begin{abstract}
ABSTRAK
Latar Belakang : Nyeri pinggang bawah merupakan gangguan berupa nyeri yang terlokalisasi antara tulang rusuk 12 dan lipatan glutealis bawah, dengan atau tanpa sakit pada kaki. Nyeri pinggang bawah merupakan gangguan tulang belakang yang dapat menyebabkan timbulnya nyeri sehingga menyebabkan gangguan mobilitas dan fungsional sehingga menghambat aktivitas pekerjaan dan aktivitas kegiatan sehari-hari. Metode : Jenis penelitian ini adalah quasy experiment di lapangan dengan menggunakan rancangan pretest-posttest two group. Populasi penelitian adalah pasien nyeri pinggang bawah non spesifik yang berusia 20 - 40 tahun yang datang berobat di klinik fisioterapi Rumah Sakit Umum Labuang Baji Makassar yang berjumlah 35 orang. Hasil : Hasil analisis wilcoxon test menunjukkan adanya perbedaan hasil pengukuran aktualitas nyeri lumbal sebelum dan sesudah pemberian William flexion $(p=0,018<0,05)$. Demikian halnya pada pemberian Mc. Kenzie $(p=0,018<0,05)$. Hasil analisis Mann-whitney test menunjukkan tidak ada perbedaan yang signifikan setelah pemberian William flexion dengan Mc. Kenzie terhadap pengukuran aktualitas nyeri lumbal $(p=0,068<0,05)$. Jika dilihat pada selisih rata-rata, maka selisih rata-rata pemberian William flexion lebih besar dibanding pemberian Mc. Kenzie. Kesimpulan : Kesimpulan penelitian yaitu ada perbedaan pengaruh antara pemberian William flexion dengan Mc. Kenzie, dimana jika dilihat pada selisih rata-rata pemberian William flexion menunjukkan pengaruh yang lebih baik.
\end{abstract}

Kata kunci: Low back pain non spesifik, William flexion dan Mc. Kenzie.

\section{ABSTRACT}

Background: Low back pain is a disorder in the form of localized pain between rib 12 and lower gluteal fold, with or without leg pain. Low back pain is a spinal disorder that can cause pain, causing mobility and functional impairments, thus hindering work activities and daily activities. Method: This type of research is a quasy experiment in the field using a two group pretest-posttest design. The study population was non-specific low back pain patients aged 20 - 40 years who came for treatment at the physiotherapy clinic of Labuang Baji Makassar General Hospital, totaling 35 people. Results: The results of the Wilcoxon test analysis showed that there were differences in the results of measuring the actuality of lumbar pain before and after William Flexion administration $(p=0.018<0.05)$. Likewise the gift of Mc. Kenzie $(p=0.018<0.05)$. The results of the Mann-Whitney test analysis showed that there was no significant difference after giving William Flexion with Mc. Kenzie on the actuality measurement of lumbar pain $(p=0.068<0.05)$. If we look at the difference in average, then the average difference in giving William Flexion is greater than that of Mc. Kenzie. Conclusion: The conclusion of this research is that there is a difference in the effect between giving William Flexion and Mc. Kenzie, where if we look at the difference in the average distribution of William flexion, it shows a better effect.

Key words: Non specific low back pain, William flexion and Mc. Kenzie.

\section{PENDAHULUAN}

Nyeri pinggang bawah saat ini merupakan suatu keadaan yang menyebabkan terjadinya inefisiensi pada suatu pekerjaan dan merupakan kondisi yang paling banyak membutuhkan perawatan kesehatan. Hal ini akan menyebabkan timbulnya gangguan dalam produktifitas kerja sehingga secara langsung dan tidak langsung akan mempengaruhi ekonomi (Andini, 2015). Aspecific Low Back Pain adalah nyeri punggung yang paling sering terjadi, diperkirakan $70-80 \%$ dari seluruh populasi pernah mengalami non-spesifik low back pain pada masa hidupnya. Prevalensi pertahunnya bervariasi dari 15\%- $45 \%$ (Purnamasari, 2010). Non specific low back pain sering menyebabkan keterbatasan dalam melakukan aktifitas fungsional (Lin,et al., 2011) menyebabkan tingginya angka tidak masuk kantor di sebagian belahan dunia, tingginya beban ekonomi pada 
individu, keluarga, masyarakat, industri dan pemerintahan (Hoy, 2010).

Sekitar 65\%-80\% manusia akan mengalami nyeri pinggang pada satu waktu selama hidupnya. Kebanyakan kejadian nyeri pinggang tidak mengakibatkan kecacatan. Lebih dari $50 \%$ penderita nyeri pinggang membaik dalam 1 minggu, sementara lebih dari $90 \%$ merasa lebih baik dalam 8 minggu. Sisanya sekitar 7\% - 10\% mengalami keluhan yang berlanjut sampai lebih dari 6 bulan (Silawati, 2009).

Prevalensi ketidakmampuan beraktivitas akibat nyeri pinggang bawah meningkat sejalan dengan bertambahnya usia yaitu sekitar $60 \%$ pada wanita dan $40 \%$ pada laki-laki (Andini, 2015). Lanjut Andini nyeri pinggang bawah merupakan gangguan muskuloskeletal yang banyak dialami pada populasi usia muda dan dewasa. Sekitar 50\% dari seluruh populasi yang mengalami gangguan muskuloskeletal adalah nyeri punggung bawah. Prevalensi ketidakmampuan beraktivitas akibat nyeri pinggang bawah meningkat sejalan dengan bertambahnya usia yaitu sekitar $60 \%$ pada wanita dan $40 \%$ pada laki-laki.

Di Amerika Serikat, sebagian besar orang yang berusia 45 tahun keatas mengalami nyeri pinggang bawah yang menyebabkan keterbatasan aktivitas. Menurut penelitian Walker dalam Silawati (2009), selama 6 bulan menunjukkan bahwa sebanyak $42,6 \%$ orang dewasa di Australia mengalami nyeri pinggang bawah intensitas rendah dan intensitas nyeri tersebut menyebabkan keterbatasan aktivitas, dan sebanyak $10,5 \%$ mengalami nyeri pinggang bawah intensitas nyeri yang tinggi dan keterbatasan aktivitas yang tinggi pula.

Hasil observasi mulai bulan Nopember 2016 - Januari 2017 di Rumah Sakit Umum Labuang Baji Makassar, menunjukkan bahwa sekitar 35 pasien nyeri pinggang bawah non spesifik yang berkunjung di Poliklinik Fisioterapi dalam tiga bulan umumnya ditemukan problem keterbatasan fleksi lumbal karena nyeri sekitar $70 \%$ dari seluruh pasien yang berkunjung. Problem ini menyebabkan fleksibilitas erector spine mengalami penurunan.

Hasil penelitian Sakti Ekawati dalam Silawati, 2009 yang membandingkan antara teknik William Flexion Exercise dengan Bugnet Exercise menunjukkan bahwa pemberian William Flexion Exercise sedikit lebih besar menghasilkan penurunan nyeri pinggang yaitu 0,7 daripada Bugnet Exercise sebesar 0,5.

Berdasarkan hal diatas, maka penulis tertarik untuk melakukan penelitian dengan judul "Pengaruh Pemberian Latihan William Flexion Dengan Mc. Kenzie Terhadap Penurunan Nyeri Pinggang Bawah Non Spesifik di Rumah Sakit Umum Labuang Baji Makassar". Adapun rumusan masalah penelitian ini yaitu apakah ada perbedaan pengaruh antara pemberian latihan William flexion dengan latihan Mc. Kenzie terhadap penurunan nyeri pinggang bawah non spesifik. Tujuan penelitian ini untuk mengetahui pengaruh pemberian latihan william flexion dengan Mc. Kenzie terhadap penurunan nyeri pinggang bawah non spesifik di Rumah Sakit Umum Daerah Labuang Baji Makassar.

\section{PROSEDUR DAN METODE Jenis Penelitian}

Penelitian ini dilaksanakan di Rumah Sakit Umum Labuang Baji Makassar. Waktu penelitian bulan Pebruari sampai dengan September 2017 dengan masa pengambilan data bulan Maret sampai dengan Mei 2017. Penelitian ini adalah penelitian eksperimen dengan desain pre test - post test two group. Populasi dan Sampel

Populasi penelitian ini adalah pasien nyeri pinggang bawah non spesifik yang berusia $20-45$ tahun yang datang berobat di klinik fisioterapi Rumah Sakit Umum Labuang Baji Makassar. Selanjutnya populasi tersebut dibatasi dengan kriteria inklusi, sehingga jumlah populasi sebesar 35 orang.

Sampel dalam penelitian ini adalah penderita Non spesifik low back pain di RSUD Labuang Baji Makassar sesuai dengan kriteria inklusi dalam pengambilan sampel. Pengambilan sampel di lakukan dengan 
menggunakan teknik purposive sampling sehingga di peroleh jumlah sampel sebanyak 14 orang.

\section{Kriteria inklusi :}

1. Tidak memiliki riwayat penyakit khusus seperti penyakit ginjal yang dapat mengganggu penelitian

2. Mengalami nyeri lumbal akibat low back pain non spesifik dengan aktualitas nyeri pada pengukuran VAS 4-9.

Kriteria eksklusi:

1. Penderita nyeri punggung bawah yang tergolong spesifik low back pain.

2. Pasien yang menderita diabetes, mempunyai riwayat penyakit ginjal atau gangguan organ internal lainnya.

\section{Besar sampel}

Berdasarkan rumus pengambilan sampel yaitu:

$$
n=\frac{N Z 21-a / 2 \text { s2 }}{(N-1) d 2+Z 21-a / 2 s 2}
$$

Maka di peroleh besar sampel sebanyak 6,48 Dengan demikian besar sampel $6-7$ orang dikali dua kelompok = 14 .

\section{Prosedur pengumpulan data}

Pada tahap pelaksanaan, setiap sampel diukur tingkat nyerinya menggunakan Visual Analoque Scale (VAS) sebagai data pre test. Kemudian diberikan perlakuan yang sama setiap responden, yaitu William flexion exercise dan mc kenzi. Setelah itu, pada akhir penelitian diukur kembali tingkat nyeri yang dirasakan sampel, sebagai data post test.

1. Alat yang di gunakan :

a. VAS untuk mengukur aktualitas nyeri lumbal.

b. Bed tempat pasien berbarin dan latihan

c. Alat tulis menulis

2. Pelaksanaan:

a. Menjelaskan garis pada Visual Analog Scale, dimana di awal garis tidak ada nyeri dan pada akhir garis merupakan nyeri tak tertahankan.
b. Pasien intruksikan untuk menandai garis tersebut sesuai dengan nyeri yang ia rasakan.
c. Mencatat hasil pengukuran.

\section{Prosedur Pelaksanaan intervensi}

1. William flexion exercise

a. Latihan 1 (pelvic tilting): pasien tidur terlentang dengan kedua knee fleksi dan kaki datar di atas bed. Datarkan punggung bawah melawan bed tanpa kedua tungkai mendorong ke bawah.

b. Latihan 2 (single knee to chest): pasien tidur terlentang dengan kedua knee fleksi dan kaki datar di atas bed. Secara berlahan tarik knee kea rah shoulder pada sisi yang simetris.

c. Latihan 3 (double knee to chest): tarik knee kiri dan kanan kea rah dada dan dapat diikuti dengan fleksi kepala atau leher.

d. Latihan 4 (partial sit-up): lakukan pelvic tilting, angkat secara berlahan-lahan kepala dan shoulder dari bed.

e. Latihan 5 (hamstring stretch): posisi long sitting dan kedua knee ekstensi penuh. Secara berlhan-lahan fleksikan trunk ke depan dengan menjangkau sejauh mungkin sampai mencapai jarijati kaki.

f. Latihan 6 (hip flexor stretch): letakkan satu kaki di depan dengan fleksi knee dan satu kaki di belakang dengan knee dipertahankan luruh, kemudian fleksikan trunk ke depan sampai knee kontak dengan lipatan axilla.

g. Latihan 7 (squat): pasien dengan posisi berdiri, punggung lurus dan kedua lengan lurus di samping Kemudian perlahan jongkok.

Semua gerakan latihan tersebut di atas (latihan 1 - 7) dilakukan 8 kali pengulangan gerakan dengan frekuensi 3 kali seminggu selama 6 kali pengobatan.

2. Mc Kenzie exercise

a. Latihan 1: tidur tengkurap dengan kepala rotasi ke satu sisi dengan kedua lengan rileks di samping badan. Kemudian dilakukan deep breathing kemudian rileks. 
b. Latihan 2: Tetap dalam posisi tengkurap, kemudian posisikan kedua tangan di bawah shoulder dalam posisi press-up. Kemudian angkat dada ke atas dengan kedua elbow dalam posisi 900 menyanggah dengan mendorong badan ke atas sejauh mungkin sehingga nyeri berkurang.

c. Latihan 3: tetap posisi tengkurap, kemudian posisikan kedua tangan $\mathrm{d}$ bawah shoulder dalam posisi press-up kemudian luruskan elbow dengan mendorong badan ke atas sejauh mungkin

d. Latihan 4: berdiri tegak dengan kedua kaki sedikit membuka. Letakkan kedua tangan dipinggang dengan jari-jari menghadap ke belakang, kemudian ekstensikan trunk sejauh mungkin dengan kedua tangan sebagai fulcrum.

e. Latihan 5: posisi tidur terlentang, kemudian bengkokkan kedua knee dan kedua kaki datar pada bed. Kemudian bawa kedua knee kea rah dada dengan bantuan kedua tangannya secara berlahan sampai kedua knee dekat dengan dada.

f. Latihan 6: posisi duduk di kursi atau stool dengan kedua knee dan kaki terbuka dan kedua tangan bersandar di atas kedua tungkai. Kemudian bengkokkan trung ke depan sehingga kedua tangan menyentuh lantai.

Semua gerakan latihan tersebut di atas (latihan 1 - 6) dilakukan 8 kali pengulangan gerakan dengan frekuensi 3 kali seminggu selama 6 kali pengobatan.

\section{Hipotesis Penelitian}

Hipotesis dalam penelitian ini adalah ada perbedaan pengaruh tekhnik William flexion dengan tekhnik mc kenzi terhadap penurunan nyeri pinggang bawah non spesifik low back pain.

\section{Analisa data}

hasil uji normalitas data menunjukkan data tidak berdistribusi normal maka digunakan uji statistik non-parametrik yaitu uji wilcoxon dan uji mann-whitney.

\section{HASIL PENELITIAN}

Hasil yang ditampilkan pada tabel 1 . Umur pasien nyeri pinggang bawah non spesifik yang terbanyak berada pada kategori umur 41 - 45 tahun, yaitu 5 orang atau $35,71 \%$. Artinya bawah subjek dalam penelitian ini umumnya berusia di atas 40 tahun.

Pada tabel 2. Jenis kelamin pasien nyeri pinggang bawah non spesifik yang terbanyak adalah jenis kelamin laki-laki. Artinya bahwa jenis kelamin laki-laki lebih besar kemungkinannya terkena nyeri pinggang bawah non spesifik dibanding jenis kelamin perempuan.

Hasil uji wilcoxon yang ditampilkan tabel 3 pada aktualitas nyeri sebelum dan sesudah pemberian latihan William flexion menunjukkan adanya perbedaan aktualitas nyeri dengan nilai signifikan $p=0,018<0,05$, dimana aktualitas nyeri sebelum latihan 6,91 $\pm 0,98 \mathrm{~cm}$ dengan aktualitas nyeri terendah $5,6 \mathrm{~cm}$ dan aktualitas nyeri tertinggi $8,6 \mathrm{~cm}$, sedangkan aktualitas nyeri sesudah latihan $2,10 \pm 0,95 \mathrm{~cm}$ dengan aktualitas nyeri terendah $1,1 \mathrm{~cm}$ dan aktualitas tertinggi 3,7 $\mathrm{cm}$ dan selisih rata-rata 4,81 $\pm 0,75$ dengan aktualitas nyeri terendah $3,4 \mathrm{~cm}$ dan aktualitas nyeri tertinggi $5,8 \mathrm{~cm}$, artinya terdapat penurunan aktualitas nyeri setelah diberikan latihan William flexion pada frekuensi pengobatan 3 kali seminggu selama dua minggu atau 6 kali pengobatan.

Hasil uji wilcoxon yang ditampilkan tabel 4 pada aktualitas nyeri sebelum dan sesudah pemberian latihan Mc. Kenzie menunjukkan adanya perbedaan aktualitas nyeri dengan nilai signifikan $p=0,000<0,05$, dimana aktualitas nyeri sebelum latihan 7,04 $\pm 1,10 \mathrm{~cm}$ dengan aktualitas nyeri terendah $6,0 \mathrm{~cm}$ dan aktualitas nyeri tertinggi $8,7 \mathrm{~cm}$, sedangkan aktualitas nyeri sesudah latihan $3,19 \pm 1,07 \mathrm{~cm}$ dengan aktualitas nyeri terendah $2,0 \mathrm{~cm}$ dan aktualitas tertinggi 5,4 $\mathrm{cm}$ dan selisih rata-rata $3,84 \pm 0,74$ dengan aktualitas nyeri terendah $3,2 \mathrm{~cm}$ dan aktualitas nyeri tertinggi $5,4 \mathrm{~cm}$, artinya terdapat penurunan aktualitas nyeri setelah 
diberikan latihan Mc. Kenzie pada frekuensi pengobatan 3 kali seminggu selama 6 kali pengobatan. Dengan demikian latihan Mc. Kenzie dapat menurunkan aktualitas nyeri pasien nyeri pinggang bawah non spesifik.

Hasil analisis pada tabel 5 menunjukkan bahwa nilai $p=0,097>0,05$, bahwa tidak ada perbedaan yang signifikan nilai aktualitas nyeri pasien nyeri pinggang bawah non spesifik di Rumah Sakit Umum Labuang Baji antara kelompok yang diberikan latihan William flexion dengan latihan Mc. Kenzie, artinya kedua modalitas tersebut mempunyai efek yang sama terhadap penurunan aktualitas nyeri pasien nyeri pinggang bawah non spesifik setelah diterapi pada frekuensi pengobatan 3 kali seminggu selama 2 minggu atau 6 kali terapi.

\section{PEMBAHASAN}

Karakteristik Umum Pasien Nyeri Pinggang Bawah Non Spesifik. Deskripsi sampel pada penelitian ini terdiri atas deskripsi berdasarkan umur dan jenis kelamin. Berdasarkan umur diperoleh data bahwa rata-rata sampel tergolong ke dalam usia dewasa. Umur subjek pada penelitian ini umumnya berusia di atas $31-40$ tahun

Faktor jenis kelamin yang terbanyak mengalami nyeri pinggang bawah non spesifik adalah jenis kelamin laki-laki dibanding perempuan. Hal tersebut terjadi karena adanya perbedaan aktivitas otot antara laki-laki dengan perempuan, dimana kekuatan otot wanita hanya $60 \%$ dari kekuatan otot laki-laki sehingga dalam beraktivitas laki-laki lebih banyak menerima beban kerja yang besar dibanding perempuan sehingga otot laki-laki mempunyai kemungkinan cidera lebih besar (Esther, 2012; Kalangi, 2015).

1. Nilai Aktualitas Nyeri Sebelum dan Sesudah Pemberian William Flexion Pasien Nyeri Pinggang Bawah Non Spesifik.

Hasil uji disimpulkan bahwa pemberian perlakuan latihan William Flexion yang mengutamakan kontraksi fleksi lumbal secara isotonik secara berulang yang dilakukan 3 kali seminggu selama dua minggu pengobatan mempunyai pengaruh terhadap perubahan aktualitas nyeri lumbal pasien nyeri pinggang bawah non spesifik.

Pemberian latihan William flexion sangat efektif untuk mengurangi aktualitas nyeri lumbal akibat nyeri pinggang bawah non spesifik tersebut. Hal tersebut dapat dicapai karena dengan pemberian latihan William flexion akan menghasilkan terjadinya penguluran pada otot fleksor panggul dan punggung bawah (m.sacrospinalis) sehingga dapat menghasilkan keseimbangan antara otototot flessssssksor postural dengan otototot ekstensor postural. Dengan demikian dapat disimpulkan bahwa latihan William flexion dapat menurunkan aktualitas nyeri pasien low back pain non spesifik setelah diberikan dengan frekuensi pengobatan 3 kali seminggu selama 2 miggu atau 6 kali terapi.

2. Nilai Aktualitas Nyeri Sebelum dan Sesudah Pemberian Mc. Kenzie Pasien Nyeri Pinggang Bawah Non Spesifik.

Latihan Mc. Kenzie dapat mengurangi nyeri pasien nyeri pinggang bawah non spesifik setelah diberikan terapi dengan frekuensi 3 kali seminggu selama dua minggu atau 6 kali terapi.

3. Perbandingan Nilai Aktualitas Nyeri Pasien Nyeri Pinggang Bawah Non Spesifik Setelah Intervensi Antar Kelompok.

Hasil uji menunjukkan tidak ada perbedaan terhadap aktualitas nyeri pasien nyeri pinggang bawah non spesifik antara kelompok yang diberikan latihan William flexion dengan kelompok yang diberikan latihan Mc. Kenzie. Hal tersebut terjadi karena kedua bentuk latihan tersebut pada prinsipnya sama, namun yang membedakan adalah bentuk gerakannya, dimana pada teknik William flexion lebih menitik beratkan pada gerakan fleksi lumbal dengan tujuan menghilangkan kurva lordosis yang berlebihan guna mengurangi spasme dan nyeri otot lumbal, sedangkan teknik Mc. Kenzie lebih menitik beratkan pada 
gerakan ekstensi lumbal dengan tujuan agar otot lumbal semakin kuat dan otot antagonis mengalami penguluran sehingga diperoleh rileksasi dan penurunan nyeri. Namun jika dilihat pada selisih rata-rata nilai aktualitas nyeri sebelum dan sesudah diberikan terapi pada kedua modalitas, maka selisih ratarata nilai aktualitas nyeri kelompok yang diberikan william flexion lebih besar. Artinya pemberian William flexion mempunyai pengaruh lebih besar dibanding Mc. Kenzie terhadap penurunan nyeri lumbal pasien nyeri pinggang non spesifik.

Hal tersebut dapat terjadi karena pada latihan Mc. Kenzie dapat menyebabkan peningkatan endorphin dan mengubah persepsi rasa sakit melalui pengurangan kecemasan dan depresi (Esther, 2012).

\section{KESIMPULAN}

1. Pemberian latihan Willian flexion mempunyai pengaruh yang signifikan terhadap penurunan aktualitas nyeri lumbal pasien nyeri pinggang bawah non spesifik.

2. Pemberian latihan Mc. Kenzie mempunyai pengaruh yang signifikan terhadap penurunan aktualitas nyeri lumbal pasien nyeri pinggang bawah non spesifik.

3. Tidak ada perbedaan pengaruh yang signifikan antara pemberian latihan William flexion dengan latihan Mc. Kenzie terhadap penurunan aktualitas nyeri lumbal pasien nyeri pinggang bawah non spesifik, namun jika dilihat pada perbedaan selisih rata-rata kedua kelompok perlakuan menunjukkan bahwa pemberian latihan William flexion mempunyai pengaruh yang lebih besar dibanding pemberian latihan Mc. Kenzie.

4. Untuk mengatasi aktualitas nyeri lumbal akibat nyeri pinggang bawah non spesifik, sebaiknya fisioterapis dapat menggunakan latihan William flexion
5. Perlu adanya penelitian lebih lanjut dengan metode penelitian yang baik dan disain dosis terapi serta teknik modalitas yang lebih jelas.

\section{DAFTAR PUSTAKA}

Allegri, Montella, Salici, Valente, Marchesini, 2016, Mechanisms of Low Back Pain: a Guide for Diagnosis and Therapy, PMC Journal, Vol. 5

Andini, 2015, Risk Factors of Low Back Pain in Workers, Journal Mayority, Vol. 4, No. 1, hal. 12 - 19.

Borestein and Wissel. 2004. Low Back Pain Medical Diagnosis and Comprehensive Management, WB Saunders Company, Philadelphia, hal. 147- 16

Braddom, 2011. Physical Medicine and Rehabilitation, $4^{\text {th }}$ Ed., Sounders, USA.

Bukhori, 2010, Hubungan Faktor Resiko Pekerjaan Dengan Terjadian Keluhan Musculoskeletal Disorder (MSDs) Pada Tukang Angkut Beban Penambang Emas di Kecamatan Cilograng Kabupaten Lebak, Skripsi, Universitas Islam Negeri Syarif Hidayatullah, Jakarta.

Cameron, 2009, Physical Agents in Rehabilitation From Research to Practice, $3^{\text {th }}$ ed., Sounders, Oregon.

Clare, Adams, Maher, 2004, A Systematic Rreview of Efficacy of McKenzie Therapy for Spinal Pain, Australian Journal of Physiotherapy, Vol. 50, pp. $209-219$.

Dreisinger, 2007, Pain Relief from McKenzie Treatment, Spine-health https://www.spinehealth.com/wellness/exercise/painrelief-mckenzie-treatment $<$ Accest at, $\underline{12}, 8-2017>$

Dubin, Patapoutian, 2010, Nociceptors: the Sensors of the Pain Pathway, The Journal of Clinical Investigation, Vol. 120 , No. 11 , pp. 3760-3772. 
Esther, 2012, Therapeutic Exercises in the Management of Non-Specific Low Back Pain, Intech-therapeutic.

Fathoni, Handoyo, swasti, 2009, Hubungan Sikap dan Posisi Kerja Dengan Low Back Pain pada Perawat di RSUD Purbalingga, Jurnal Keperawatan Soedirman, Vol. 4 No. 3, hal. 131 139.

Fitrianty, 2008, Study Tentang Hubungan Antara Perubahan Postur Akibat Overweight Terhadap Kejadian Nyeri Pinggang bawah di RSUP Dr. Wahidin Sudirohusodo dan RSAD Pelamonia Makassar, Poltekkes Makassar.

Gupta, 2015, A Comparison Between McKenzie extentions exercise Versus Williams flexion exercises for Low Back Pain in BPT. Students, Indian Journal of Physical Therapy Vol.3 No.2, pp. $51-55$.

Hindle, Withcomb, Briggs, Hong, 2012, Proprioceptive Neuromuscular Facilitation (PNF): Its Mechanisms and Effects on Range of Motion and Muscular Function, Journal of Human Kinetic, Vol. 31, pp. 105 113.

Houglum, 2009, Examination of Musculoskeletal Injuries 4th Edition, USA

Hooper, 1999, Williams' Flexion Exercises vs. McKenzie's Extension Protocol, Journal Dynamic Chiropractic.

Hoy, Brooks, Blyth, Buchbinder, 2010, The Epidemiology of Low Back Bain, Best Practice \& Research Clinical Rheumatology Journal, Vol. 24, No. 6, pp. 769-781.

Idyan, 2007, Hubungan Lama Duduk Saat Perkuliahan Dengan Keluhan Low Back Pain. http://www.innappni.or.id $<$ acces at, 8, 12-2017>

Iswadi, 2010, Beda Pengaruh Antara Pemberian Shortwave Diathermy dan Latihan Mc. Kenzie Dengan Shortwave Diathermy dan Latihan William Flexion Terhadap Perubahan
Fleksibilitas Otot Erector Spine Lumbal Pada Penderita Nyeri Pinggang Bawah di Rumah Sakit Umum Islam Faisal Makassar, Skripsi, Poltekkes Kemenkes Makassar.

Kapandji. 2010. The Physiology of The Joint. Volume Two. Churchill Living Company, USA, hal. 68-81.

Kisner and Kolby, 2007, Therapeutic ExerciseFoundation and Techniques, $5^{\text {th }}$ ed., Adavies Company, Phyladelphia, USA.

Kisner C, Allen LC, 2012, Therapeutic Exercise Foundation and Techniques, $6^{\text {th }}$ ed., FA. Davis Company, Philadelphia, 164 - 178, $309-310$,

Kroemer K and Grandjean E., 1997, Fitting the Task to The Human : A textbook of Occupational Ergonomics, $5^{\text {th }}$ ed., Taylor \& Francis, London, pp. 121 125.

Kuntoro, 2011, Dasar Filosofis Metodologi Penelitian, Pustaka Melati, Surabaya.

---------, 2010, Metode Sampling dan Penentuan Besar Sampel, Pustaka Melati, Surabaya

Liebenson, Craig, 2005, Mc.Kenzie SelfTreatments for Sciatica, Journal of Bodywork and Movement Therapies, Elsevier, USA.

Lin, Mc Auley, Macedo, Barnett, 2011, Relationship Between Physical Activity and Disability in Low Back Pain: A Systematic Review and Meta-analysis, Pain Journal, Vol. 152 , pp. $607-613$.

McDowel, Johnson, Hetherington, 2014, Mulligan Consep Manual Therapy: Standadizing Annotation, Journal Manual Therapy, Vol. 19, pp. 499 503.

Moore, K. L., dan Dalley, A. F. 2004. Clinical Oriented Anatomy. Philadelphia : Lippincott Williams \& Wilkins.

Parjoto,2006, Pelatihan Penatalaksanaan Fisioterapi Komprehensif pada 
Nyeri, Universitas Diponegoro, Semarang.

Patricia, Smithy, Katz, 2015, Pain Complaints and Cognitive Status among Elderly Institution Residents, Journal of the American Geriatric Society, Vol. 41, No. 5 , pp. $517-522$.

Ponte, Jensen, Kant, 2004, A Preliminary Report on the Use of the McKenzie Protocol versus Williams Protocol in the Treatment of Low Back Pain, The Journal of Orthopaedi and Sport Physical Therapy, Vol. 6 No. 2, pp. $130-139$.

Pramita, Pangkahila, Sugijanto, 2015, Core Stability Exercise Lebih Baik Meningkatkan Aktivitas Fungsional dari pada William's Flexion Pada Pasien Nyeri Punggung Bawah, Sport and Fitness Journal, Vol. 3, No. 1, hal. $35-49$.

Purnamasari,2010, Over Wight sebagai Faktor Risiko Low Back Pain pada Pasien Poli Saraf RSUD Prof.Dr.Margono Soekarjo Purwekerto, Mandala of Health. Vol. 4, No. 1, hal. $26-32$.

Putz, R., dan Pabst, R. 2006. Atlas Anatomi Manusia Sobotta. Jakarta : Buku Kedokteran, EGC. Penerbit Buku Kedokteran Jakarta:

Rydeard, Leger, Smith, 2006, Pilates-Based Therapeutic Exercise: Effect on Subjects With Nonspecific Chronic Low Back Pain and Functional Disability: A Randomized Controlled Trial, Journal Orthopaedic Sports Physical Therapy, Vol. 36, No. 7, pp. 472 484.

Santoso, 2003. Pengaruh Perubahan Letak Titik Berat dan Titik Tumpu Tubuh
Kerja Bubut Posisi Berdiri Terhadap Kelelahan Otot Biomekanik. Disertasi, Universitas Airlangga, Surabaya.

Sakinah, Rafael, Furqaan, 2012, Faktor yang Berhubungan dengan KeluhanNyeri Punggung Bawah pada Pekerja Batu-bata di Kelurahan Lawawoi Kabupaten Sidrap. (KTIS). Makassar: FKM UNHAS.

Silawati, 2009, Efektifitas SWD dan William Flexion Exercise Dengan US dan William Flexion Exercise Terhadap Fleksibilitas Lumbal di RSUP Dr. Wahidin Sudirohusodo Makassar, Skripsi, Poltekkes Makassar.

Wahyuni, 2011, Perbedaan Efektivitas Antara terapi Latihan William Flexion Dengan Mc. Kenzie Extention Pada Pasien Yang Mengalami Postural Low Back Pain, Skripsi, Universitas Udayana Denpasar.

Waqqar, Rahman, Ahmad, 2016, McKenzie Treatment Versus Mulligan Sustained Natural Apophyseal Glides for Chronic Mechanical Low Back Pain, Pak J Med Sci., Vol.32(2), pp. 476-479.

Werner, P. 2008. Sistem Lokomotor dan Topografi. Edisi 6. EGC Penerbit Buku Kedokteran Jakarta.

Wulandari, Maja, Khosama, 2013, Gambaran Faktor yang Mempengaruhi Nyeri Punggung Bawah pada Buruh Kapal, Jurnal E-Clinic, Vol. 2, No. 1. Yanuar, Andre. 2002. Anatomi, Fisiologi dan Biomekanika Tulang Belakang, Simposium Managemen Terpadu Nyeri Punggung Bawah, Surakarta. 
Tabel 1

Distribusi Frekuensi Umur Pasien Nyeri Pinggang Bawah Non Spesifik di Rumah Sakit Umum Labuang Baji Tahun 2017

\begin{tabular}{ccc}
\hline $\begin{array}{c}\text { Kategori } \\
\text { Umur }\end{array}$ & Frekuensi & $\begin{array}{c}\text { Persentase } \\
\text { (\%) }\end{array}$ \\
\hline $20-25$ tahun & 1 & 7,14 \\
\hline $26-30$ tahun & 3 & 21,43 \\
\hline $31-35$ tahun & 2 & 14,29 \\
\hline $36-40$ tahun & 3 & 21,43 \\
\hline $41-45$ tahun & 5 & 35,71 \\
\hline Total & $\mathbf{1 4}$ & $\mathbf{1 0 0}$ \\
\hline Sumber $:$ Data Primer, 2017 &
\end{tabular}

Tabel 2

Distribusi Frekuensi Jenis kelamin Pasien Nyeri Pinggang Bawah Non Spesifik di Rumah Sakit Umum Labuang Baji Makassar Tahun 2017

\begin{tabular}{lcc}
\hline \multicolumn{1}{c}{ Jenis Kelamin } & Frekuensi & $\begin{array}{c}\text { Persentase } \\
(\%)\end{array}$ \\
\hline Laki-laki & 10 & 71,43 \\
\hline Perempuan & 4 & 28,57 \\
\hline \multicolumn{1}{c}{ Total } & $\mathbf{1 4}$ & $\mathbf{1 0 0}$ \\
\hline Sumber : Data Primer, 2017 & &
\end{tabular}

Tabel 3

Analisis Aktualitas Nyeri Sebelum dan Sesudah Pemberian William Flexion Pasien Nyeri Pinggang Bawah Non Spesifik di Rumah Sakit Umum Labuang Baji Makassar Tahun 2017

\begin{tabular}{llllll}
\hline \multirow{2}{*}{$\begin{array}{l}\text { Waktu } \\
\text { Pengukuran }\end{array}$} & \multicolumn{4}{c}{ Nilai Aktualitas Nyeri } & \multirow{2}{*}{$\mathrm{P}$} \\
\cline { 2 - 5 } & Mean & SD & Min & Mak & \\
\hline $\begin{array}{l}\text { Sebelum } \\
\text { Latihan }\end{array}$ & 6,91 & 0,98 & 0,6 & 0,6 & \\
\hline $\begin{array}{l}\text { Sesudah } \\
\text { Latihan }\end{array}$ & 2,10 & 0,95 & 0,1 & 0,7 & 0,018 \\
\hline Selisih rata-rata & 4,81 & 0,75 & 0,4 & 0,8 & \\
\hline
\end{tabular}

Sumber : Data Primer, 2017 


\section{Tabel 4}

Analisis Aktualitas Nyeri Sebelum dan Sesudah Pemberian Latihan Mc. Kenzie Pasien Nyeri Pinggang Bawah Non Spesifik di Rumah Sakit Umum Labuang Baji Makassar Tahun 2017

\begin{tabular}{|c|c|c|c|c|c|}
\hline \multirow{2}{*}{$\begin{array}{l}\text { Waktu } \\
\text { Pengukuran }\end{array}$} & \multicolumn{4}{|c|}{ Nilai Aktualitas Nyeri } & \multirow{2}{*}{$\mathrm{P}$} \\
\hline & nean & SD & $\mathrm{Mn}$ & Max & \\
\hline $\begin{array}{l}\text { Sebelum } \\
\text { Latihan }\end{array}$ & 0,04 & 0,10 & 6,0 & 0,7 & \multirow{3}{*}{$\begin{array}{l}0,0 \\
18\end{array}$} \\
\hline $\begin{array}{l}\text { Sesudah } \\
\text { Latihan }\end{array}$ & 0,19 & 0,07 & 2,0 & 0,8 & \\
\hline $\begin{array}{l}\text { Selisih rata- } \\
\text { rata }\end{array}$ & 0,84 & 0,74 & 3,2 & 0,4 & \\
\hline
\end{tabular}

Sumber : Data Primer, 2017

Tabel 5

Analisis Aktualitas Nyeri Pasien Nyeri Pinggang Bawah Non Spesifik Setelah Latihan Antar Kelompok di Rumah Sakit Umum Daerah Labuang Baji Makassar Tahun 2017

\begin{tabular}{llll}
\hline Variabel & $\begin{array}{l}\text { Mea } \\
\mathbf{n}\end{array}$ & SD & $\mathbf{P}$ \\
\cline { 1 - 3 } William & 2,10 & 0,95 & \multirow{2}{*}{0,09} \\
Flexion & & \multicolumn{1}{l}{0,07} & \\
\cline { 1 - 3 } Mc. kenzie & 3,19 & 1,07 &
\end{tabular}

Sumber : Data Primer, 2017 